\title{
Segurança em Edifícios Sistemas de Circuito Fechado de Televisão
}

\section{Enquadramento}

Para que os ocupantes e operadores possam usufruir na plenitude dos edifícios, estes devem satisfazer requisitos arquitectónicos, funcionais, ecológicos, económicos e de segurança.

O fim e a utilização a que se destina cada edifício determinam a selecção, instalação e implementação de diferentes medidas de protecção e segurança, de forma a assegurar e controlar os aspectos de segurança das diversas valências das instalações, equipamentos e ocupantes.

Independentemente do risco ou complexidade de cada instalação, deverão ser estudados, desenvolvidos e implementados sistemas de protecção e segurança, capazes de garantir o conforto e a segurança dos ocupantes e a protecção de bens.

A segurança contra incêndios, nas áreas de redução e protecção do risco, são a principal vertente da segurança em edifícios. A segurança contra intrusão, controlo de acessos, videovigilância e alarmes técnicos são outras vertentes fundamentais no garante da segurança em edifícios.

\section{A Videovigilância como Valência de Segurança em Edifícios}

É cada vez mais frequente o recurso à videovigilância através de sistemas de circuitos fechados de televisão (Closed Circuit Television - CCTV), quer como elementos isolados de vigilância, quer como elementos de complemento do' sistemas de segurança, em geral, e, em particular sistemas de detecção automática de intrusão e controlo de acessos.

Embora existam dispositivos pertencentes ao CCTV que podem realizar a detecção automática de intrusão, os sistemas de CCTV não são, habitualmente, designados de sistemas de segurança, mas sim, sistemas de vigilância. Não tendo por isso, normalmente, uma missão de vigilância com detecção automática de intrusão, mas sim a vigilância como elemento de suporte ao controlo e à intervenção humana.

Além da visualização de imagem, em tempo real, os sistemas de CCTV permitem a gravação e arquivo dessas mesmas imagens, que posteriormente poderão ser consultadas, se tal for necessário.

A instalação de sistemas de CCTV é, assim, hoje em dia, um facto generalizado motivado, por um lado, pela necessidade de proceder ao controlo e à protecção de pessoas e bens e, por outro, pelo reduzido custo destes sistemas.

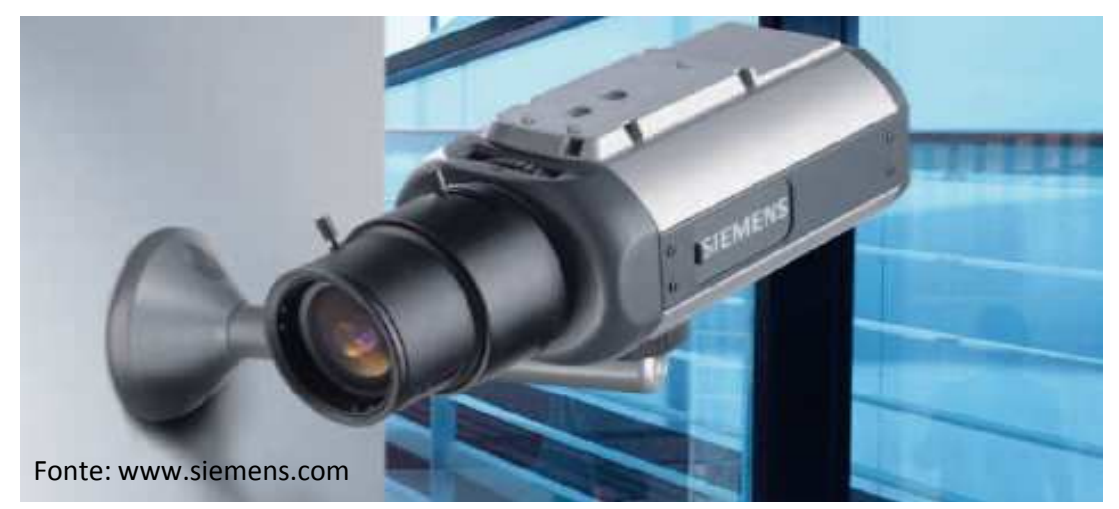




\section{3. Áreas de Intervenção dos Sistemas de Videovigilância}

A utilização dos sistemas de videovigilância através de sistemas de Circuito Fechado de Televisão encontra-se, actualmente, generalizada a todas as áreas de actividade, desde a comercial, industrial, serviços, recintos desportivos, estabelecimentos de ensino, actividade portuária e aeroportuária, vias de circulação até à área residencial.

De entre as inúmeras vantagens da utilização de sistemas de CCTV, podemos destacar

- Aumento da segurança física das instalações;

- Aumento da segurança e do conforto dos utilizadores das instalações;

- Facilidade no controlo dos acessos de pessoas internas e externas às organizações;

- Facilidade no controlo de viaturas próprias e externas às organizações;

- Supervisão de pontos de venda e atendimento a clientes;

- Controlo e gestão eficaz em processos produtivos;

- Controlo mais eficaz das instalações;

- Possibilidade de acesso remoto via internet, de qualquer ponto do mundo, em tempo real;

- Flexibilidade na utilização do sistema.

Como utilização mais comum dos sistemas de CCTV, podemos destacar a vídeo vigilância e segurança em:

- Estabelecimentos comerciais;

- Bancos;

- Oficinas;

- Edifícios públicos;

- Portos e aeroportos;

- Moradias.

Outras aplicações, mais específicas da utilização de sistemas de CCTV são:

- Monitorização de tráfego em pontes e estradas;

- Monitorização de processos industriais;

- Vigilância de áreas interditas à presença humana tais como: fornos, zonas tóxicas, submersas, etc.

- Vigilância de sítios sem iluminação;
- Vigilância de veículos de transporte público (comboios, metro, barcos, ...);

- Vigilância de zonas públicas em hotéis, casinos;

- Vigilância de parques de estacionamento;

- Vigilância de zonas pedonais;

- Análise facial para identificação de pessoas;

- Sondas médicas;

\section{Arquitectura de um Sistema de Videovigilância}

A arquitectura de um sistema de videovigilância pode ser dividida em quatro grupos principais:

\section{- Recolha de imagem}

Corresponde às unidades que fazem a transformação do sinal óptico (imagem) em sinal eléctrico, sendo constituída pelos elementos de conversão da zona visualizada num sinal de vídeo.

É composto essencialmente pelas câmaras, lentes, suportes e caixas.

\section{- Transmissão do sinal}

Responsável pelo transporte do sinal recolhido pelo grupo anterior, até à zona de processamento, controlo e comando e monitorização da imagem.

A transmissão do sinal é realizada, essencialmente, por cabo coaxial, par troçado ou cabo de fibra-óptica.

\section{- Processamento do sinal, controlo, comando e gravação da imagem}

Constituído pelo conjunto de equipamentos responsáveis pelo processamento, controlo e comando e gravação da imagem, proveniente do grupo de recolha.

É composto essencialmente selectores, multiplexadores e gravadores. 


\section{ARTIGO TÉCNICO}

\section{- Monitorizarão da Imagem}

Constituído pelos equipamentos de recepção do sinal de vídeo, que voltam a fazer a transformação do sinal eléctrico em sinal óptico, observável pelo olho humano e que permite a visualização das imagens.

A monitorização da imagem é realizada em monitores dedicados ou em monitores de computadores.

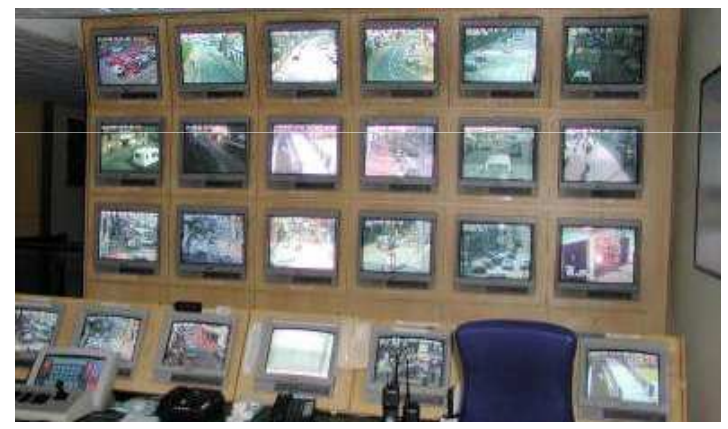

Figura 1 - Vista Geral de uma Sala de Segurança

\section{Tecnologia dos Sistemas de Videovigilância}

- Tipo de Sistemas
- Analógico
- Digital

Nos sistemas digitais, destacamos o sistema IP (Internet Protocol), que pode-se dizer, veio revolucionar os sistemas de videovigilância, uma vez que permite novas funcionalidades como o acesso ao sistema, através de uma rede interna, ou à distância, via internet.

\section{- Tipos de Lentes}

o Focagem variável ou fixa;

o Íris manual ou automática

o Filtros IR

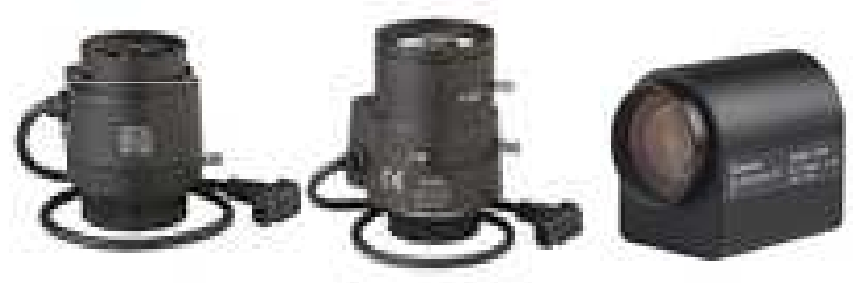

Figura 2 - Diversos tipos de lentes de um sistema de videovigilância

\section{- Tipos de Câmaras}
o Fixas
o MiniDome
o SpeedDome

Podendo ser a preto e branco, cor ou day/night.
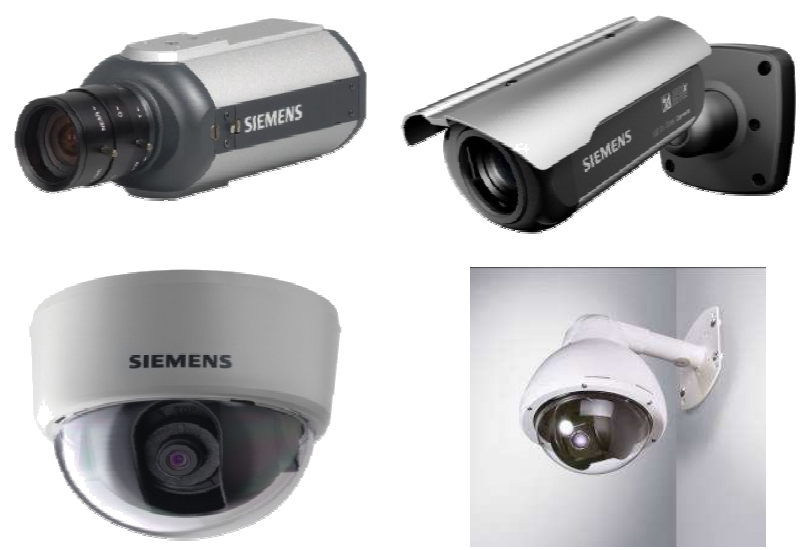

Figura 3 - Diversos tipos de câmaras de um sistema de videovigilância

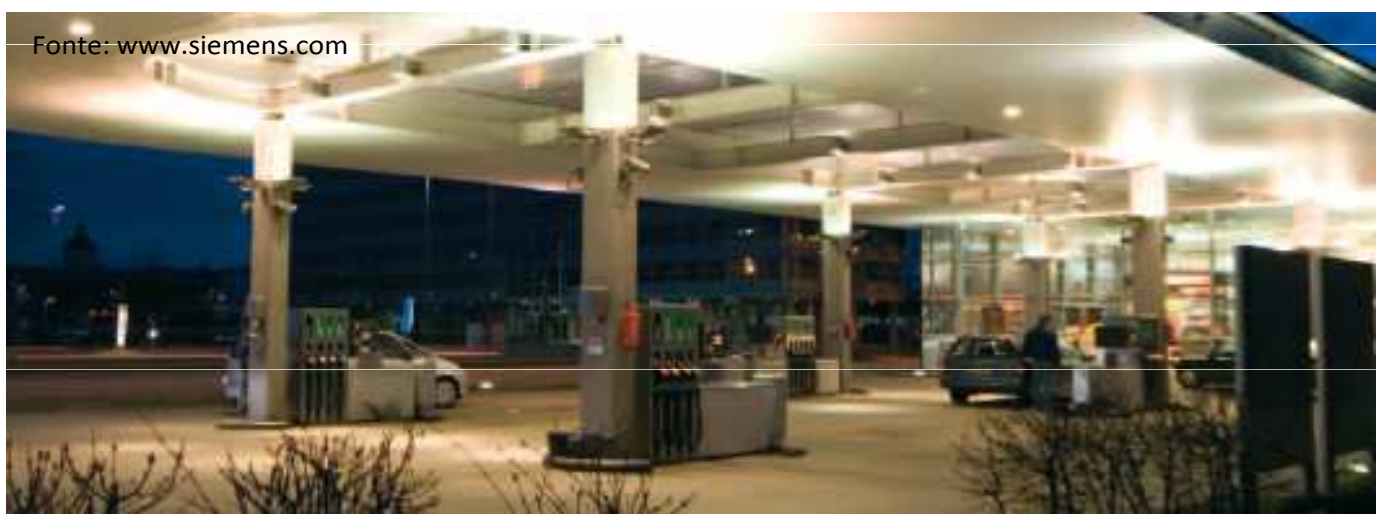




\section{- Suportes e caixas}

Os suportes são os elementos de fixação das câmaras.

As caixas são os elementos de protecção e, por vezes, de dissimulação das câmaras.

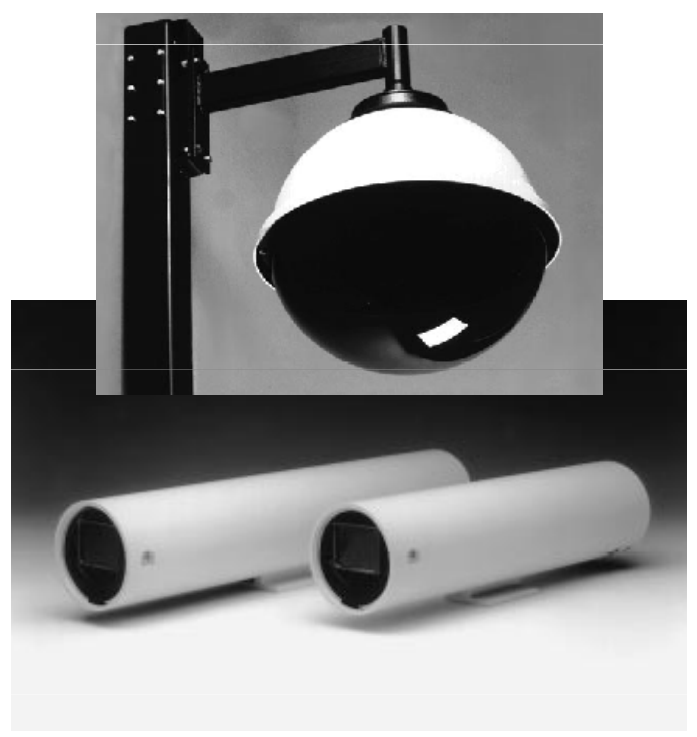

Figura 4 - Suportes e caixas

\section{- Monitores}

Embora ainda se encontrem em utilização monitores do tipo CRT (cathode ray tube), os monitores mais largamente utilizados hoje em dia são do tipo TFT (Thin Film Transmitter).

Os monitores podem ser monocromáticos ou policromáticos.

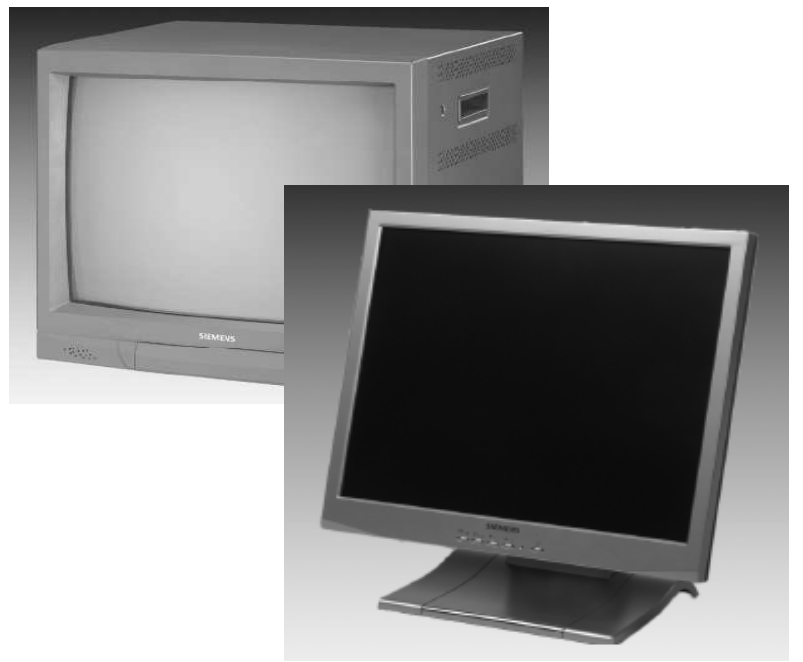

Figura 5 - Monitores CRT e TFT

\section{- Gravador}

É o elemento responsável pela gravação das imagens, para posterior visualização.

- Gravadores Analógicos

São a solução tradicional para a gravação do sinal de vídeo. São aparelhos que permitem a gravação do sinal de vídeo em fitas magnéticas, bastante semelhantes aos aparelhos domésticos.

Com o surgimento dos sistemas digitais este tipo de solução de gravação da imagem está a cair em desuso .

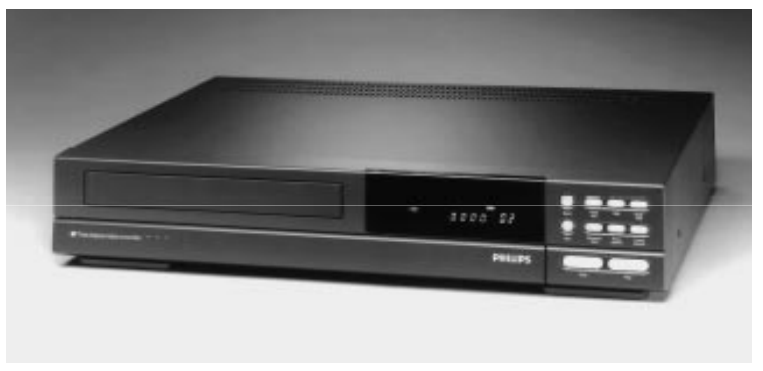

Figura 6 - Gravador analógico

- Gravadores digitais

Actualmente, com o surgimento do digital e dos sistemas IP, a gravação é realizada em discos duros de sistemas dedicados (gravadores digitais autónomos) ou nos discos dos computadores.
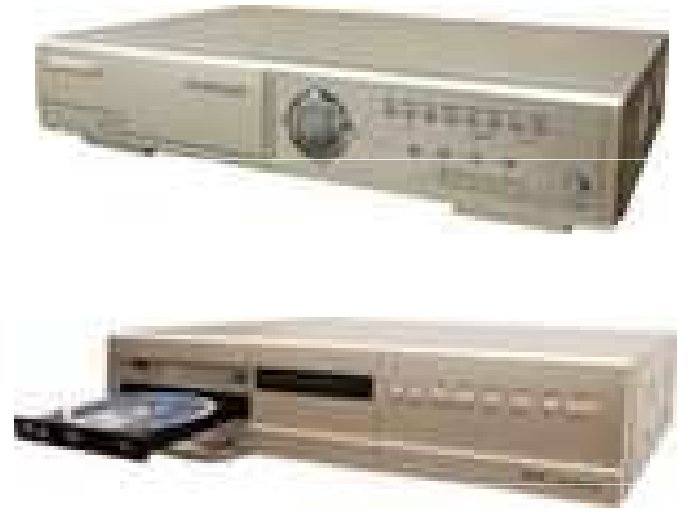

Figura 7 - Gravador digital 


\section{ARTIGO TÉCNICO}

\section{Arquitectura Geral dos Sistemas de Videovigilância}

De seguida apresentam-se alguns exemplos de configurações gerais de sistemas de CCTV, envolvendo as diversas tecnologias anteriormente descritas.

- Sistema tradicional
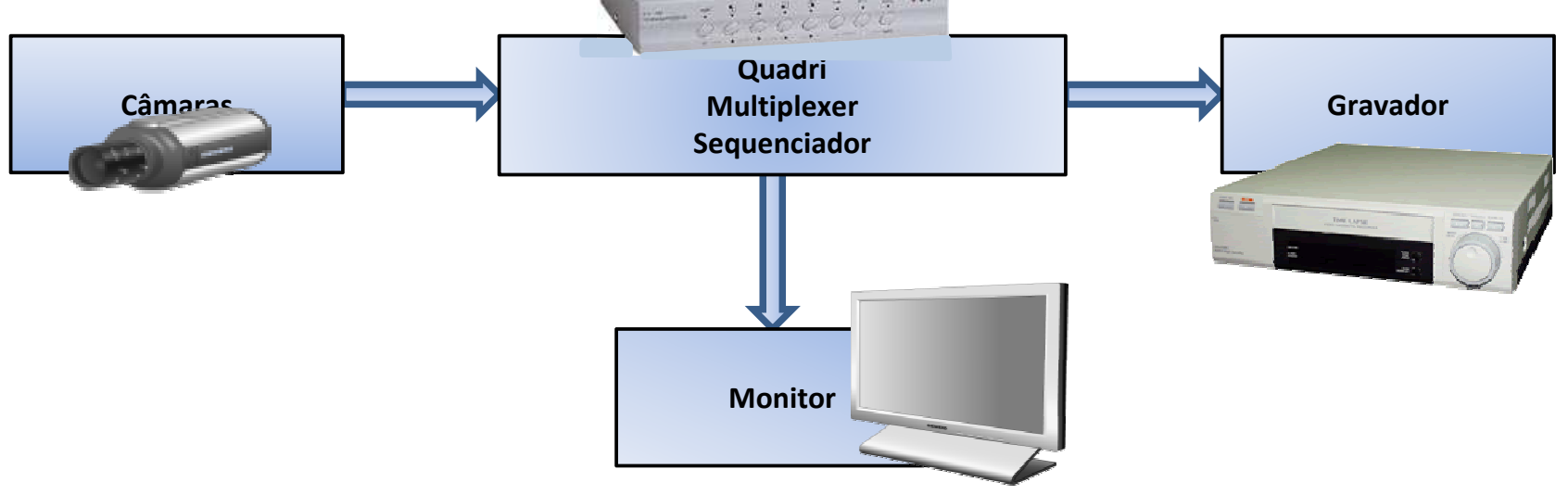

- Sistema com Gravador Digital Simples

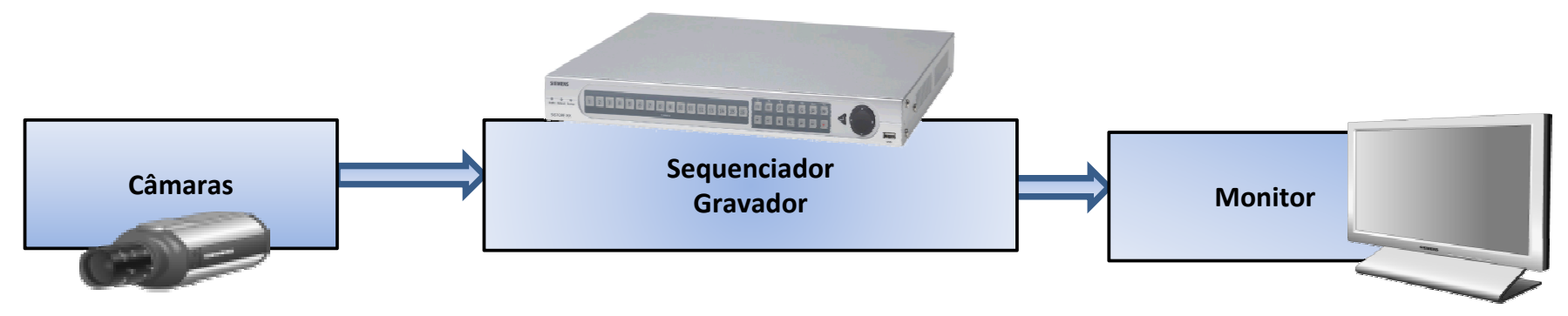

- Sistema com Transmissão por TCP/IP
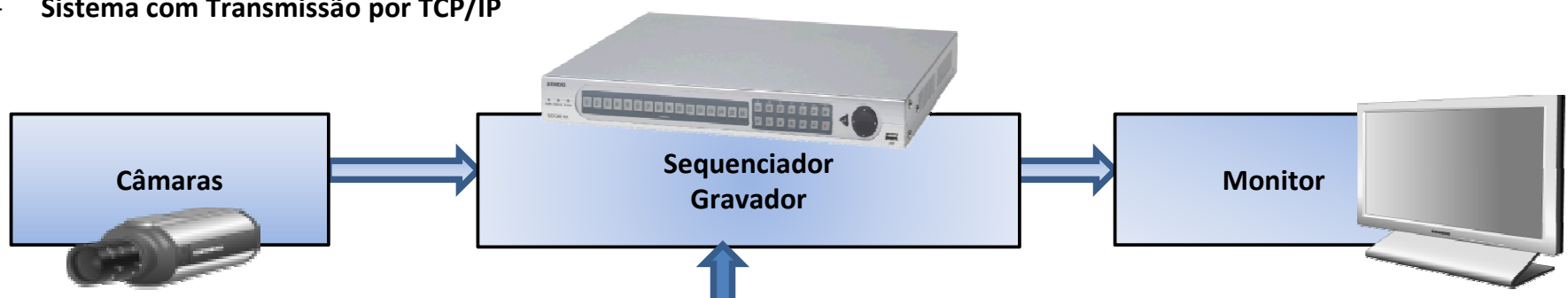

FロGL

- ISRN

- PGTN

- ETHERNET

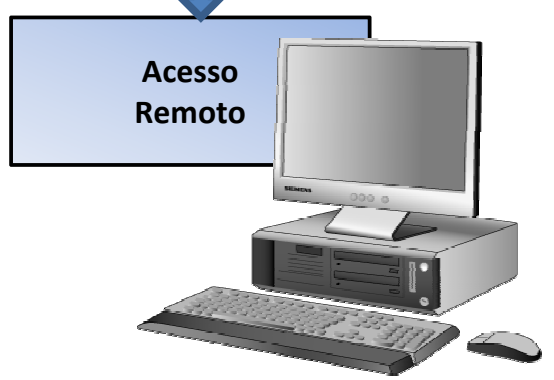




\section{Conclusão}

Os sistemas de videovigilância são cada vez mais uma importante valência na segurança dos edifícios, de forma a garantir a segurança de pessoas instalações e bens.

A instalação de sistemas de Circuito Fechado de Televisão é, hoje em dia, um facto generalizado motivado, por um lado, pela necessidade de proceder à protecção de pessoas e bens e, por outro, pela flexibilidade e baixo preço destes sistemas.

Actualmente os sistemas de Circuito Fechado de Televisão estão presentes em todas as áreas de actividade, desde o comércio, industria, até ao sector habitacional.

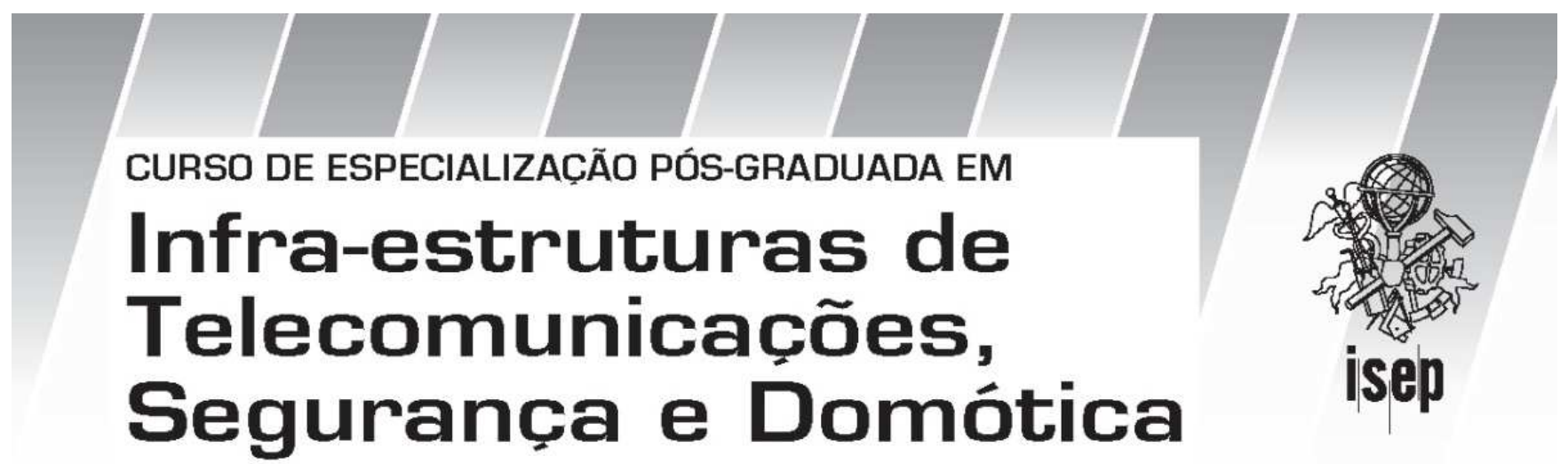

OBJECTIVOS GERAIS E ENQUADRAMENTO

Promover competências aos pós-graduados no âmbito do projecto, execução e fiscalizaçâo de instalações de infra-estruturas telefónicas em edificios e urbanizaçóes, sistemas de segurança, domótica e gestăo técnica centralizada.

\section{DESTINATÁRIOS}

0 curso destinase a bacharéis e licenciados recém formados na área da Engenharia Electrotécnica e/ou Engenharia Electrónica, assim como quadros no activo que pretendam adquirir competências no âmbito das telecomunicações, segurança e domótica

LOCAL

ISEP. Instituto Superior de Engenharia do Porto

R. Dr. António Bernardino de Almeida, 431, 4200072 Porto Tel: 228340500 - Fax: 228321159

info: jbc@isep.ipp.pt

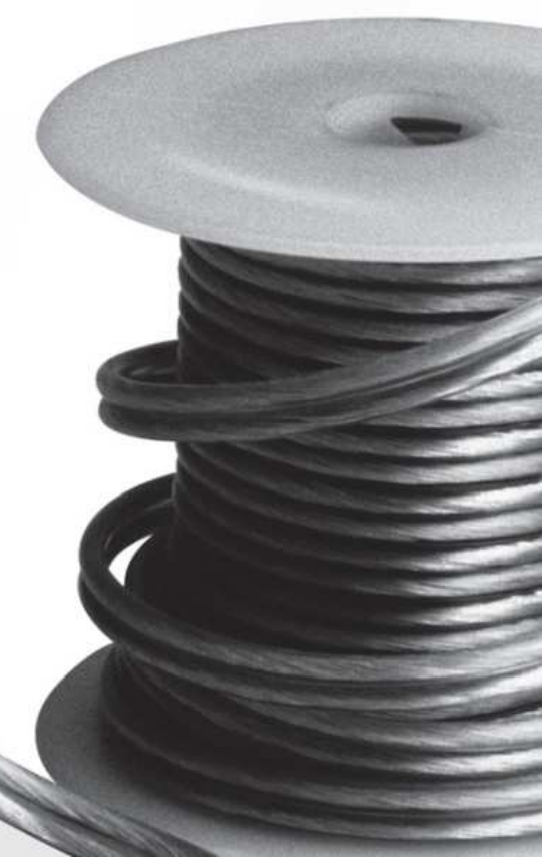

